\title{
The Effect of Size and Material of Packing Seal and Pump Flow Rate to Leakage Rate at Stuffing Box of Centrifugal Pump
}

\author{
Mohd Zafuan Mohd Zainal ${ }^{1,2}$, Mohd Yusri Mohd Yunus ${ }^{1,3^{*}}$ and Aaina Syakirah Nor \\ Azizan $^{3}$, Nurul Ain Ismail ${ }^{1,3}$ \\ ${ }^{1}$ Fakulti Teknologi Kejuruteraan Kimia Dan Proses, Universiti Malaysia Pahang, 26300, Kuantan, Pahang, \\ Malaysia \\ ${ }^{2}$ Petronas Technical Training Sdn. Bhd. (956097-W), Lot 9764, Batu Rakit 21020 Kuala Nerus, Terengganu \\ Malaysia \\ ${ }^{3}$ Pusat Kelestarian Ekosistem \& Sumber Alam, Universiti Malaysia Pahang, 26300, Kuantan, Pahang, Malaysia \\ *Email: yusri@ump.edu.my
}

\begin{abstract}
This research explores the effect of size and material of packing seal and discharge valve opening on the leakage rate at the stuffing box for pump P7301-A. Leak at the stuffing box is unavoidable due to a gap between the pump casing and shaft. Therefore, it is necessary for a suitable sealing system that includes packing size and material to be installed on all pumps to control the leakage rate without damaging the pumps. It is also important for the operator to know the proper discharge valve opening at which the pump should be operated to get minimum leakage. The experiment was conducted by recording the leakage volume at the stuffing box with changes of size $(9 \mathrm{~mm}, 10 \mathrm{~mm}$, and $11 \mathrm{~mm}$ ) and material (graphite, polytetrafluoroethylene (PTFE), and PTFE-asbestos) of packing seal and discharge valve opening $(50 \%, 75 \%$, and $100 \%)$ that would determine the pump flow rate. The experiment was executed and analyzed using one factor at a time (OFAT) method whereby the testing of factors conducted one at a time instead of multiple factors simultaneously determined which setting would lead to the lowest leakage rate without compromising the pump's healthiness. A feasibility analysis was also conducted on the operating cost focusing on saving utility bills and maintenance costs that focused on painting and fitting replacement works. Results from the experiment and analysis showed that packing seal size and discharge valve opening affect leakage rate at the stuffing box. In contrast, the material of the packing seal is not significant in influencing the leakage rate of this pump. A larger size packing seal would cause a lower leakage rate due to more significant obstruction at the stuffing box. The leakage rate also declined when the discharge valve was fully opened due to less resistance created at the discharge line had reduced the pressure in the pump casing, which led to less leakage at the stuffing box. Feasibility analysis showed cost saving of MYR5,930.00 on the operating cost and cost-saving of MYR221,200.00 on the maintenance cost for 10-year operation of 10 pumps could be achieved. The outcome from this study can be utilized to reduce the plant operating cost, maintenance cost, person-hours saving, and preserve the treated water resources.
\end{abstract}

Indexed Terms- Sealing system, tanking, leaking rate, centrifugal pump

\section{INTRODUCTION}

A sealing system is a must component for any pump to prevent external leakage created by the gap between the pump casing and shaft. This gap is necessary to ensure smooth rotation of the shaft with efficient usage of power. One solution is by using a packing seal to minimize the leakage through braking mechanism created once compressed into the pump stuffing box. Packing seal is preferred as the sealing method for centrifugal pumps used for water services because of its affordable price. This seal can only be used for non-hazardous liquid such as water and could not be used for hazardous applications such as hydrocarbon, acid, or corrosive chemical substances that can harm the pump 
operator, nearby asset, and environment its working principle that must allow some leaks for lubrication. However, heat generated by the braking mechanism could deteriorate the performance of the packing seal and lead to premature failure through rapid degradation of the material. Therefore, the packing seal must leak to allow lubricant originated from the pump product to lubricate and reduce the temperature at the surface contact areas. This leakage rate must be controlled because the excessive leak could lead to pressure loss and housekeeping issues, while insufficient leak could result in premature failure of the packing seal.

The nearest study on evaluating the performance of packing seal was on predicting leakage rate based on graphite material using a gas product. Failure of the pump sealing system would contribute to plant downtime and adversely affect plant productivity. Previous research showed seal leakage rate would depend on size, temperature, application, media, pressure, and shaft speed. However, these criteria were not tested for water pumps at this training plant. Presently, pump P-7301A is using a PTFE packing seal with a size of $10 \mathrm{~mm}$. The pump is usually operated at $100 \%$ capacity with a full discharge valve opened. It is observed that the leakage rate is excessive with a range of $300-350 \mathrm{~mL}$ per minute as compared to the manufacturer's guideline of 90 drops per minute which is equivalent to $4.5 \mathrm{~mL}$ per minute. Although the pump manages to produce two barg as required by plant operation, it is a concern that the leak would grow larger and causes a pressure drop. The plant also must bear the unnecessary cost because the water is supplied by Syarikat Air Terengganu (SATU). Reducing the leak means one step to cost optimization. Apart from that, this leak has generated housekeeping issues, with algae growth has become a common sighting on its foundation.

The objectives of this study are to investigate the effect of size and material of packing seal and discharge valve opening to leakage rate (volume of a leak in one (1) minute) of a centrifugal pump at training plant and to conduct a feasibility analysis on the impact of the leakage on operating cost and maintenance cost. Leakage rate was analyzed under three (3) manipulated variables: packing seal size of $9 \mathrm{~mm}, 10 \mathrm{~mm}$ and $11 \mathrm{~mm}$, packing seal material of graphite, polytetrafluoroethylene (PTFE), and PTFE with Asbestos and discharge valve opening at 50\%, 75\%, and $100 \%$. A feasibility analysis was conducted on the impact of the leakage on operating costs and maintenance costs.

\section{RESEARCH BACKGROUND}

\subsection{Centrifugal Pump}

A pump that uses an impeller as its energy agent is known as a centrifugal pump, and this type of pump would typically accommodate up to $80 \%$ of pumps at a chemical plant. Demand for centrifugal pump depends on the application required either to get a high flow rate with low pressure or to get both high flow rate and high pressure. When a driver is supplied with power, for example, an electric motor, it will rotate the pump impeller through a drive component known as a coupling. The pump will deliver kinetic energy to the product (liquid) and convert it into pressure energy using a volute casing before releasing it to the pipeline [1]. There are five (5) basic components for a centrifugal pump, namely the impeller, casing, shaft, bearing, and seal, which are important in determining the functionality and productivity of the pump [2]. In this study, the focus will be given to seal, which is also important for the pump performance and address the wastage issue. To extend the pump's life, an excellent maintenance strategy is important to avoid unplanned breakdowns, which would significantly cost the plant owner. Unplanned downtime could result in a high cost of manpower, spare part, technical specialist fees, and most importantly, loss of production. Therefore, pumps must be adequately maintained to avoid the company having too many bills to pay.

\subsection{Sealing System}

One of the essential components of the pump is the sealing system. The objective of having a proper sealing system for a centrifugal pump is to allow the rotating shaft to enter the pump wet area without 
large volumes of pressurized liquid escaping. The fluid is forced to the impeller back by the pump discharge pressure and is induced to exit by way of the rotating shaft. The gap between the shaft and pump casing must be adequately sealed to minimize this leakage, contain the process pressure, and withstand friction caused by shaft rotation. For petrochemical and refinery plants, it is mandatory for hydrocarbon centrifugal pumps to utilize mechanical seals according to standard [3].

To ensure the packing seal serves its function effectively, Paresh Girdhar highlighted a suitable number of packing rings must be placed, and a gland follower shall be used to squeeze and press them down to the shaft in the pump stuffing box [2]. The packing pressing down to the shaft has created a braking mechanism that generates heat caused by friction between the packing and shaft. If there is too much friction, the shaft would require more power to rotate at a designated operating speed. This is where proper lubrication is required to reduce friction, prevent heat buildup, and extend the seal life span. There are so many configurations or materials available for packing seals. Normally, the original equipment manufacturer (OEM) would provide guidelines or specifications on choosing the correct seal for a specific application. However, if none is provided, one can use a general guideline in packing selection known as STAMPS which stands for size, temperature, application, media, pressure, and shaft speed. If the guideline is followed religiously, premature failure will not happen based on the packing seal selection. The size of the packing seal is critical in determining the practical sealing function. A simple formula is used to calculate its size, as shown in Equation 1. Failure to install the correct size of the packing seal could result in an excessive leak.

$$
\text { Size }=\frac{[\text { Shaft sleeve diamter (OD)-stuffing box inside diamter (ID) }]}{2}
$$

The selection of packing seal material is also important in determining its performance. There are three (3) factors that need to be considered when selecting the right packing seal material: $\mathrm{pH}$ of the pumped liquid, liquid temperature, and shaft speed. Although the main product is water which normally is neutral, it must also be compatible with either acidic or caustic liquid that is used to clean the pump. Any reaction to the packing could damage its structure and jeopardize its integrity. There are various materials available in the market, such as jute, hemp, aramid, flax, polytetrafluoroethylene (PTFE), graphite, asbestos, and the latest one developed is GFO [4]. Table 1 summarizes the properties concerning the $\mathrm{pH}$, pressure, temperature, and shaft speed.

Table 1: Summary of Different Materials Properties

\begin{tabular}{lcccc}
\hline Material & \multicolumn{4}{c}{ Service Parameters } \\
& $\begin{array}{c}\text { Temperature } \\
\left({ }^{\circ} \mathrm{C}\right)\end{array}$ & $\mathrm{pH}($ Range $)$ & Pressure (bar) & $\begin{array}{c}\text { Velocity } \\
(\mathrm{m} / \mathrm{s})\end{array}$ \\
\hline PTFE & -100 to +260 & $0-14$ & 34 & 10 \\
Graphite & -200 to +455 & $0-14$ & 34 & 20 \\
GFO & -129 to +290 & $0-14$ & 20 & 20 \\
\hline
\end{tabular}

Out of many materials available in the market, only three (3) of them are selected for this study due to their common application in the industry. They are PTFE, graphite, and GFO. However, PTFE with Asbestos was selected as the final material substituting GFO due to its unavailability. The installation method must be performed correctly according to seal manufacturer procedure or guidelines [5]. This includes cleaning and examining the shaft's condition after removal of old packing and before installing a new one. The shaft must be cleaned and polished to get a better life span for the new packing. During the installation stage, the packing rings must be arranged staggered at a minimum of $90^{\circ}$ to avoid excessive leakage during operation. In addition to that, the position of the lantern ring should be checked 
to be correct under the inlet port. Another consideration that must be considered is the operating temperature. Exceeding the limit temperature could lead to material breakdown and carbonize. Temperature consideration is critical when the application exceeds $260^{\circ} \mathrm{C}$ because many materials, including PTFE, tend to break down and carbonize at elevated temperatures. The key to proper selection is the retention of volume. The most temperature-resistant packings are carbon and graphite-based. This issue is not so critical in most rotating equipment since, in most cases, flush water is utilized. Where this selection becomes critical is with high-temperature valve packing in the petrochemical and power generation industries. The temperature may not be so critical in this study as the product temperature is at ambient temperature. Packing seal material depends on the shaft speed, which is calculated using feet per minute (FPM) on Equation 2). When the packing is forced against the shaft, frictional heat is created, thus degrading the material condition. Higher performance packing is designed to reduce friction, thus reducing heat and extending the pump's life. To get a reliable service, packing with a rating of 3,000 FPM is normally selected based on the general rule. The calculation for FPM can be referred to as an Equation 2.

$\mathrm{FPM}=($ Shaft or sleeve diameter $\times 3.14) \times \mathrm{RPM} / 12$

\subsection{One Factor at A Time (OFAT) Method}

To understand the best setting of a process, empirical experiments must be conducted at least in a local area of operation. One such experiment is by holding all inputs, but one fixed and see the best result when the one free input is varied. Fix that input at that best value. Then vary one other input. See where the best output is now. Fix the second input at that best value, and so on until all input factors run out. This is called a one factor at a time (OFAT) experiment and is practiced widely [6].

\subsection{Preventive Maintenance for Pump}

To achieve excellence in maintenance, the balance of maintenance performance, risks, and costs must be taken into account to achieve good quality solutions [7]. This includes developing tactics that maximize the benefits of maintenance strategies, usually classified into two major categories, corrective maintenance (CM) and preventive maintenance (PM). CM can originate high costs, including loss of production incurred due to equipment downtime. Therefore, PM should be performed to reduce these costs whenever it reduces the likelihood of failure occurrence. However, too many preventive maintenance interventions can also result in high costs due to unnecessary utilization of resources. Therefore, one must have a good balance between CM and PM to get the most out of it. For centrifugal pumps, PM normally involves relubrication works and visual inspection related to leak inspection [8]. The technicians or operators involved with the task would easily spot the leakage problem, and as front liners, they will take the first action before the matters exaggerate. If the design of the components is not of high quality, there will be a high consumption of maintenance time for doing that, which is not a good maintenance practice. Therefore, the result of this study can be used as a guideline for technicians to select the correct specification for maintenance time and cost optimization.

\subsection{Studies on Pump Leakage}

In order to analyze the impact of excessive pump leakage on production loss and maintenance cost, several past researches were studied. Josifovic and his colleagues explained the necessity of analyzing the pump's design space that could improve pump efficiency [9]. Low efficiency means more leakage to the environment and can be harmful. This study was conducted for plunger pumps instead of centrifugal pumps, which has been the research subject. Sorin, Aldea, \& Mădălin conducted a study on the necessary adjustment of pumping stations operating parameters to the network demands to achieve sustainable operating costs [10]. Bianchi and his group assessed the relevance of pumping work in energy recovery systems based on bottoming Organic Rankine Cycles (ORC) and presents the 
development of a sliding vane pump prototype for small-scale units [11]. The model considers the fluid dynamics and friction phenomena involved in the pump operation, such as vane filling and emptying, leakages, and dry and viscous friction between components in relative motion. The modeling platform was further exploited to retrieve performance maps of the pump, angular vane pressure evolution, and break down leakage and friction losses. This study was focusing on internal leakage involving the design of the sliding vane itself. It is not related to the centrifugal pump and leakage at the stuffing box.

Mo and his group presented important aspects of a practical methodology to design a gear pump using the ANSYS Gambit software parametric abilities followed by an FVM analysis of its assembly to identify the most stressed components [12]. The importance of this study is to understand which parts are likely to fail and could cause leakage. Ferrante and his group of researchers explained the effect of the spatial variation of the leak law parameters at the local scale on leak law determination at a global scale [13]. This involves the design of orifice, piping material, and thickness. However, this study did not focus on a centrifugal pump. Salah and his colleagues presented a study on leak rates prediction through packing rings made of soft materials such as graphite at different compression stress levels [14]. However, it focused on the gas leak for valves application where helium, nitrogen, and argon are used as the testing medium. Based on the literature review, various researches were performed onpump or seal performance, including leakage problem. Still, they did not consider the liquid leakage problem at the stuffing box for the centrifugal pump.

\section{METHODOLOGY}

\subsection{Experimental Work}

A flowchart that summarizes the experimental work can be referred as in Figure 1.

\section{Step 1: Equipment Set-Up}

Firstly, packing was cut diagonally at $45^{\circ}$ using a packing cutter. The packing was kept clean during the procedure. Then ring was installed one at a time. Used "S" twist to install ring on the sleeve. Next, the ring was pressed into the bottom of the box and seated gently with split bushing. The shaft was rotated after each ring was installed. Stagger joints $90^{\circ}$ for four ring set or more. The lantern ring was installed in the stuffing box based on the previous arrangement. The lantern ring was placed under the flush port. After that, the Gland ring was tightened slightly. The nose of the gland was inserted into the stuffing box by $1 / 8 "$. The shaft was rotated by hand. Lastly, liberal leakage was allowed at startup. Leakage flow was adjusted to an acceptable level by tightening gland nuts slowly and evenly. Final adjustments were made by rotating gland nuts one (1) flat at a time.

\section{Step 2: Experiment Procedure}

After the pump was made available for the experiment, it was operated at an ambient temperature of approximately $30^{\circ} \mathrm{C}$ in dry condition with a running speed of 1,450 RPM. After running for 10 minutes, vibration readings at the bearing housing for the electric motor and pump are recorded to verify the readiness of the experiment. The vibration value recorded was $1.2 \mathrm{~mm} / \mathrm{s}$ RMS which is less than 4.5 $\mathrm{mm} / \mathrm{s}$ RMS [15], indicating that the pump was operating at standard condition.

Once it is verified as fit for the experiment, the leakage rate would be determined by measuring the volume of leaks at the stuffing box using a measuring cylinder and beaker. Measuring leakage rate using beaker in 1 minute. The volume of the leak was measured in milliliter $(\mathrm{mL})$. The total time for collecting the leak was one (1) minute using a stopwatch. 


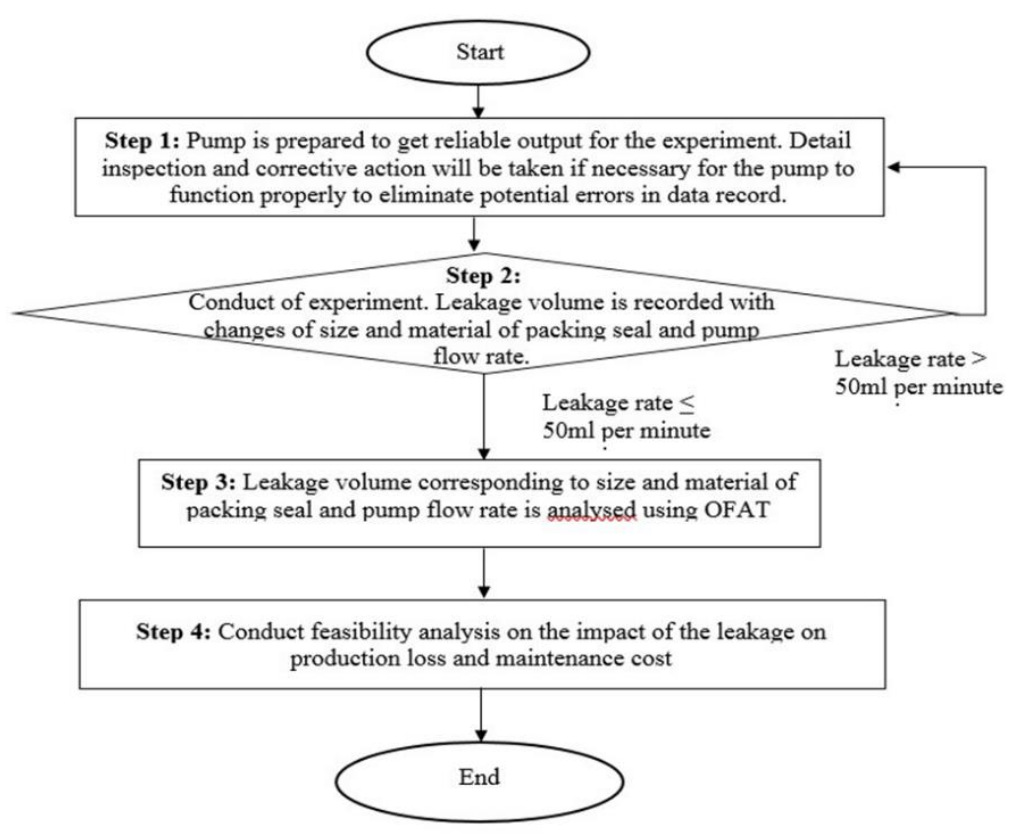

Figure 1: Experiment Flowchart

This experiment was repeated for three (3) manipulated variables as follows:

i. Packing seal sizes of $9 \mathrm{~mm}, 10 \mathrm{~mm}$, and $11 \mathrm{~mm}$

ii. Packing seal material of polytetrafluoroethylene (PTFE), graphite, and PTFE-asbestos.

iii. Discharge valve opening at 50\%, $75 \%$, and $100 \%$.

The maximum leakage rate for this experiment is capped at $50 \mathrm{~mL} / \mathrm{min}$ to eliminate external factors that could contribute to the leakage rate.

Step 3: Data Analysis

The volume of leakage measured during the experiment phase using a measuring beaker and cylinder corresponding to the manipulated variables was analyzed using one factor at a time (OFAT) technique. OFAT is suitable for this study because the result would indicate which input would most impact the outcome [6]. Based on the analysis, the effect of size and material of the packing seal and the discharge valve opening to the leakage rate of the pump could be determined. From the data analysis, an optimum setting of packing seal for this pump can be derived. A good set-up should be represented by the least leakage rate without jeopardizing the life of the seal.

Step 4: Feasibility Analysis on the Impact of Improvement Work

A feasibility analysis was simulated to measure the impact of improvement work based on the model derived from the data analysis stage should the plant agree to roll it out. The focus of the analysis was on operating costs and maintenance costs. This included calculating the leakage rate based on standard tariff and considering the number of manhours utilized in maintaining the pump due to leakage at the stuffing box. Cost-saving obtained from the improved leakage rate was calculated as follows:

$$
\text { Cost saving }=(\text { Existing leakage rate-improved leakage rate }) \mathrm{x} \text { water tariff }
$$

The difference between existing and improved leakage rate was converted to the cubic meter before being multiplied with standard tariff for water consumption in Terengganu, which is governed by Syarikat Air Terengganu Sdn Bhd. The standard tariff is MYR1.15 per $\mathrm{m}^{3}$. The cost saving is then projected for ten years to see its long-term implication on operating costs. It is then multiplied by ten 
pumps to see the impact on the whole operation. Another issue associated with leakage is corrosion rate and algae growth, which requires painting, including housekeeping and maintenance work. Manpower cost was calculated based on an estimated service rate of RM80 per hour. The calculation for painting work and fitting replacement work can be referred to Eq. 4 and Eq. 5. Cost-saving was estimated by differentiating the frequency of existing maintenance and improved maintenance for 10-year operation for ten pumps.

Service rate $\mathrm{x}$ number of personnel $\mathrm{x}$ work duration $\mathrm{x}$ cost of paints

Fittings cost $\mathrm{x}$ number of replacement

\section{RESULTS AND DISCUSSION}

\subsection{Data Collection}

In this section, the experimental results obtained for the various tests performed according to the configurations are presented in Table 4.1. The leakage rate is presented and analyzed as a function of packing material, packing size, and discharge valve opening.

\subsection{Data Analysis}

\subsubsection{Effect of Packing Size}

To simplify the study of packing size's effect on the leakage rate, the pump discharge flow rate is fixed at $100 \%$ for all packing materials of different sizes. The effect of packing size is shown in the following charts. Figure 2, Figure 3, and Figure 4 comprise graphite, PTFE, and PTFE-Asbestos recorded significant readings when different packing sizes were used to seal the pumped liquid. Figure 2 shows leakage rate for graphite packing decreased significantly from $29.3 \mathrm{~mL} / \mathrm{min}$ to $5.3 \mathrm{~mL} / \mathrm{min}$ when $9 \mathrm{~mm}$ packing size was replaced with $11 \mathrm{~mm}$.

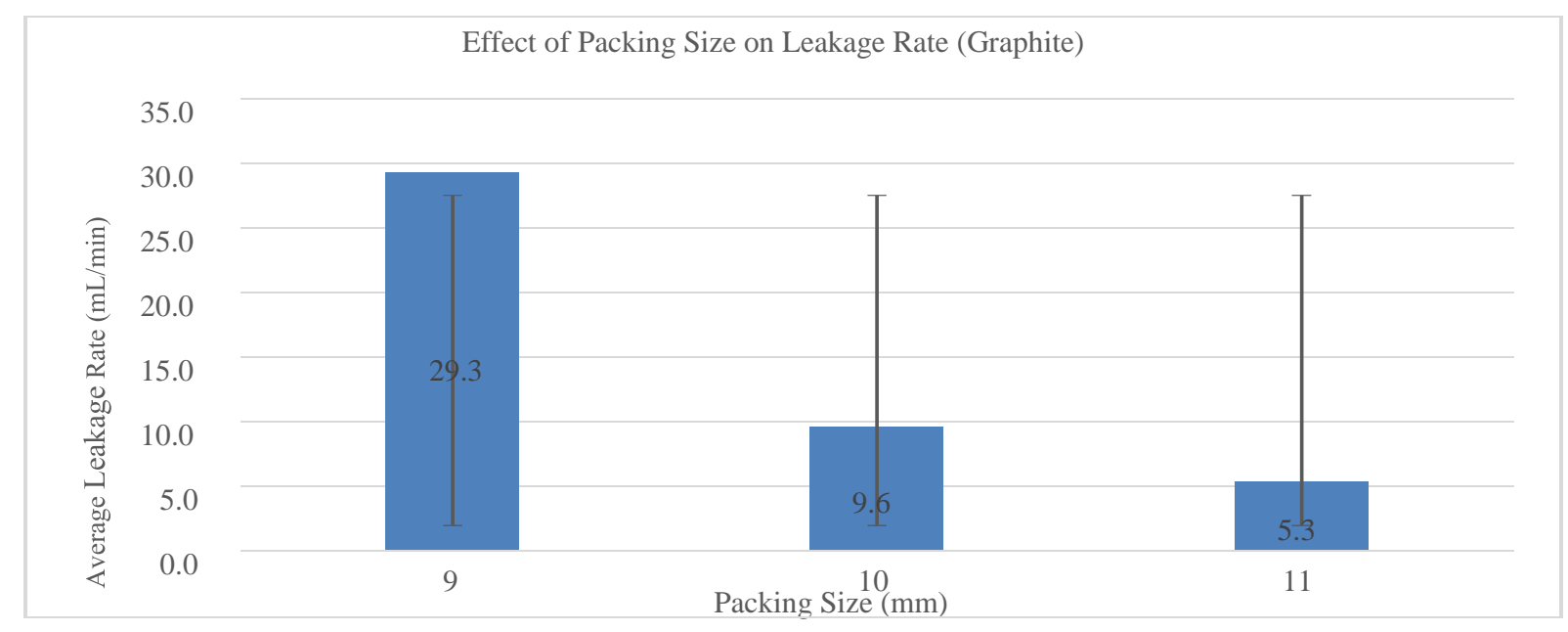

Figure 2: Effect of Packing Size on Leakage Rate (Graphite)

The same effect was observed for PTFE-asbestos packing whereby leakage rate of $29.2 \mathrm{~mL} / \mathrm{min}$ had reduced to $5.5 \mathrm{~mL} / \mathrm{min}$ based on Figure 4. Based on this result, the leakage rate of pumped liquid is influenced by the size of the packing seal regardless of packing materials. The smaller the size of the packing, the more leakage rate is observed. Despite its working principle compressed to withstand the 
Table 2: Leakage Rate of Packing Based on Experiment Configurations

\begin{tabular}{|c|c|c|c|c|c|c|c|}
\hline \multirow{2}{*}{ Material } & \multirow{2}{*}{$\begin{array}{l}\text { Size } \\
(\mathrm{mm})\end{array}$} & \multirow{2}{*}{$\begin{array}{c}\text { Discharge } \\
\text { Valve Opening } \\
(\%)\end{array}$} & \multicolumn{3}{|c|}{ Result (mL/min) } & \multirow{2}{*}{$\begin{array}{l}\text { Average } \\
(\mathrm{mL} / \mathrm{min})\end{array}$} & \multirow{2}{*}{$\begin{array}{l}\text { Standard } \\
\text { Deviation }\end{array}$} \\
\hline & & & 1 & 2 & 3 & & \\
\hline \multirow{9}{*}{ Graphite } & 9 & 50 & 31.3 & 31.7 & 31.4 & 31.5 & 0.21 \\
\hline & 9 & 75 & 31.0 & 30.8 & 31.2 & 31.0 & 0.20 \\
\hline & 9 & 100 & 29.4 & 29.1 & 29.4 & 29.3 & 0.17 \\
\hline & 10 & 50 & 11.6 & 11.5 & 11.0 & 11.4 & 0.32 \\
\hline & 10 & 75 & 11.2 & 11.5 & 10.7 & 11.1 & 0.40 \\
\hline & 10 & 100 & 10.8 & 9.0 & 9.0 & 9.6 & 1.04 \\
\hline & 11 & 50 & 6.2 & 6.5 & 6.2 & 6.3 & 0.17 \\
\hline & 11 & 75 & 5.8 & 5.2 & 5.5 & 5.5 & 0.30 \\
\hline & 11 & 100 & 5.2 & 5.5 & 5.2 & 5.3 & 0.17 \\
\hline \multirow{9}{*}{ PTFE } & 9 & 50 & 31.2 & 31.4 & 33.8 & 32.1 & 1.45 \\
\hline & 9 & 75 & 30.6 & 30.8 & 32.0 & 31.1 & 0.76 \\
\hline & 9 & 100 & 29.1 & 30.5 & 29.5 & 29.7 & 0.72 \\
\hline & 10 & 50 & 11.2 & 11.5 & 11.0 & 11.2 & 0.25 \\
\hline & 10 & 75 & 10.6 & 11.0 & 11.2 & 10.9 & 0.31 \\
\hline & 10 & 100 & 9.6 & 9.4 & 9.0 & 9.3 & 0.31 \\
\hline & 11 & 50 & 6.7 & 6.6 & 6.2 & 6.5 & 0.26 \\
\hline & 11 & 75 & 6.2 & 5.8 & 5.7 & 5.9 & 0.26 \\
\hline & 11 & 100 & 5.2 & 5.8 & 5.4 & 5.5 & 0.31 \\
\hline \multirow{9}{*}{$\begin{array}{c}\text { PTFE } \\
\text { with } \\
\text { Asbestos }\end{array}$} & 9 & 50 & 32.4 & 34.0 & 34.0 & 33.5 & 0.92 \\
\hline & 9 & 75 & 31.1 & 32.5 & 31.5 & 31.7 & 0.72 \\
\hline & 9 & 100 & 29.4 & 29.7 & 28.5 & 29.2 & 0.62 \\
\hline & 10 & 50 & 11.3 & 11.4 & 12.4 & 11.7 & 0.61 \\
\hline & 10 & 75 & 9.7 & 10.5 & 10.2 & 10.1 & 0.40 \\
\hline & 10 & 100 & 9.0 & 9.1 & 9.4 & 9.2 & 0.21 \\
\hline & 11 & 50 & 6.3 & 6.7 & 6.9 & 6.6 & 0.31 \\
\hline & 11 & 75 & 6.2 & 6.0 & 6.2 & 6.1 & 0.12 \\
\hline & 11 & 100 & 5.6 & 5.4 & 5.4 & 5.5 & 0.12 \\
\hline
\end{tabular}

pressure that amounted to the pump, casing the right packing size is vital to minimize the leak. This is due to the higher pressure build-up in the pump casing that forces the liquid to rush towards the lower pressure area, the atmosphere, through its stuffing box. However, the size of the packing seal is limited 
by the stuffing box inside diameter and shaft sleeve outside diameter. A larger packing size could also lead to a higher temperature at the stuffing box due to a lack of lubrication.

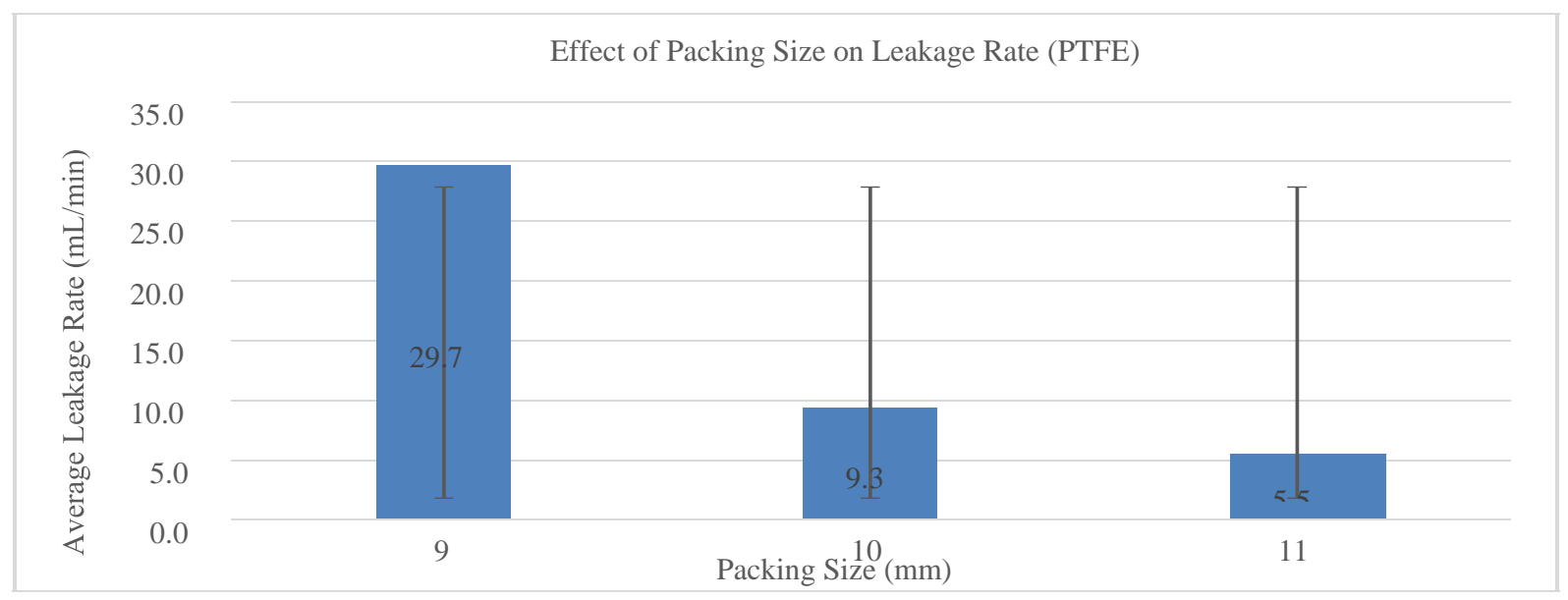

Figure 3: Effect of Packing Size on Leakage Rate (PTFE)

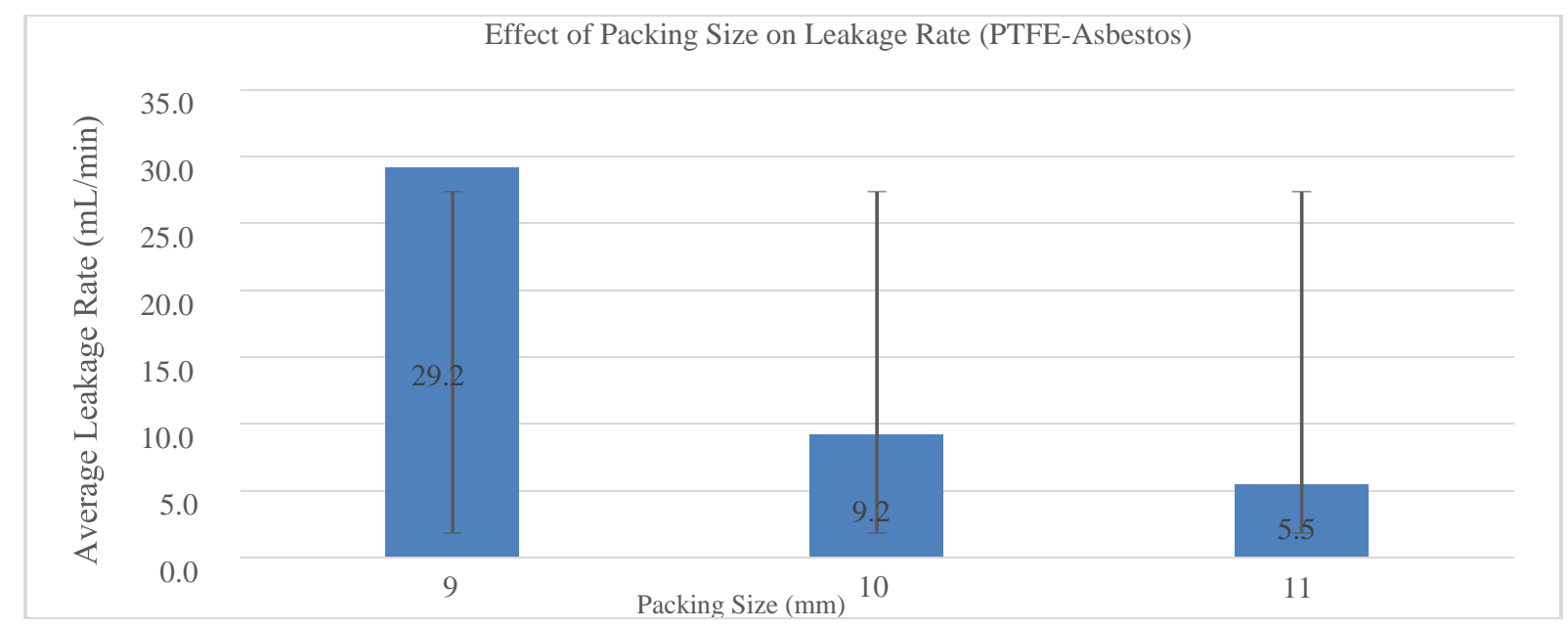

Figure 4: Effect of Packing Size on Leakage Rate (PTFE-Asbestos)

As a result, the packing will burn out prematurely and require frequent replacement. Therefore, correct packing size must be selected to avoid higher maintenance costs resulting from unnecessary labor hours, wrong consumables, and extended equipment downtime. According to the manufacturer's guideline, the packing size should be calculated based on the shaft or shaft sleeve outside diameter and the stuffing box inside diameter. Based on Equation 2.1, the optimum size is $10 \mathrm{~mm}$ or the next higher size which is $11 \mathrm{~mm}$. For better results, $11 \mathrm{~mm}$ packing should be used despite many efforts being put forward in the installation work. The leakage rate of $5.5 \mathrm{~mL} / \mathrm{min}$ is approximately equivalent to 110 drops per minute, around the acceptable leakage rate of 90 drops per minute.

\subsubsection{Effect of Discharge Valve Opening}

To simplify the study of pump discharge flow rate effect on the leakage rate, the packing size is fixed at $11 \mathrm{~mm}$, which served as the optimum size for all packing materials at different discharge valve openings. The effect of discharge valve opening can be observed in Figure 5, Figure 6, and Figure 7. 
Slight reduction of leakage rate for graphite, PTFE, and PTFE-asbestos packing was recorded when $100 \%$ pump discharge valve opening was implemented compared to $50 \%$ discharge valve opening.

For example, the average leakage rate for graphite packing dropped from $6.3 \mathrm{~mL} / \mathrm{min}$ to $5.3 \mathrm{~mL} / \mathrm{min}$ after being throttled from 50\% to $100 \%$ discharge valve opening. For PTFE packing, $1.0 \mathrm{~mL} / \mathrm{min}$ difference of leakage rate was recorded for PTFE packing when throttled from 50\% to 100\% discharge valve opening. The leakage rate for PTFE Asbestos had reduced by $1.1 \mathrm{~mL} / \mathrm{min}$ after the discharge valve opening was adjusted.

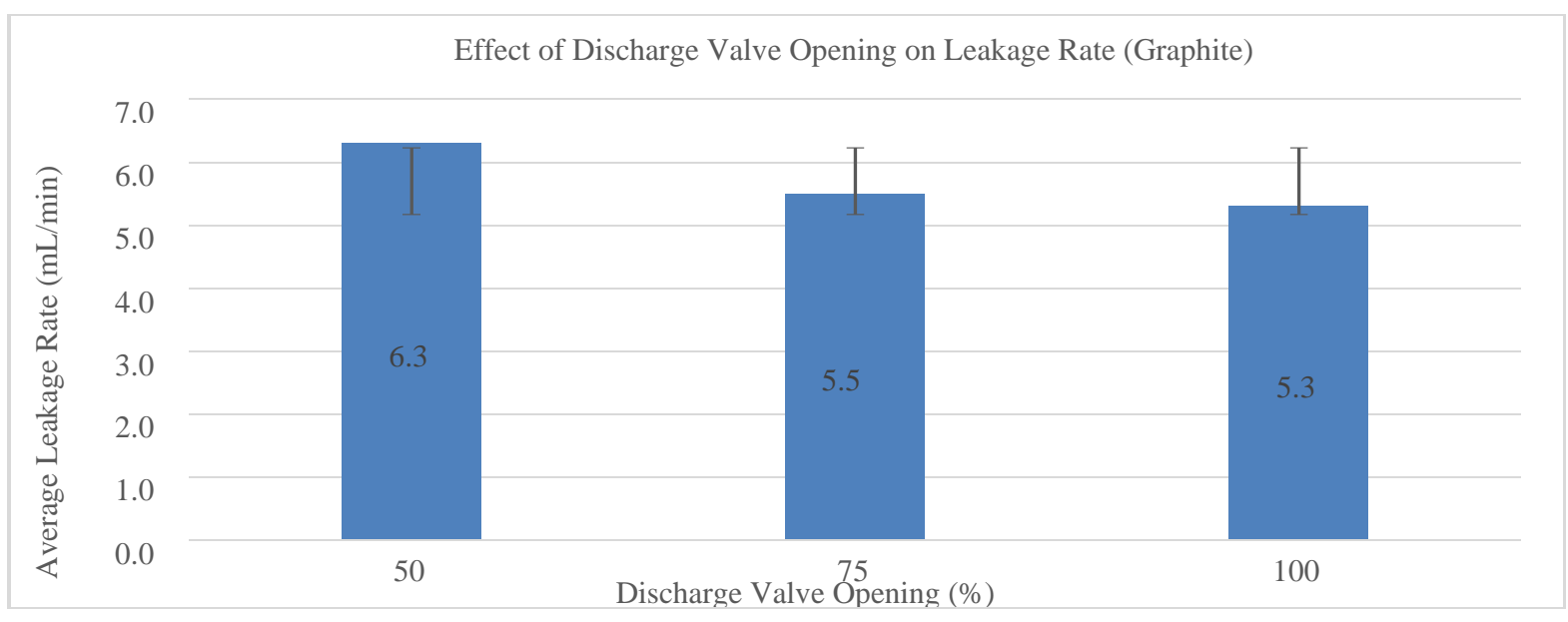

Figure 5: Effect of Pump Discharge Flow Rate on Leakage Rate (Graphite)

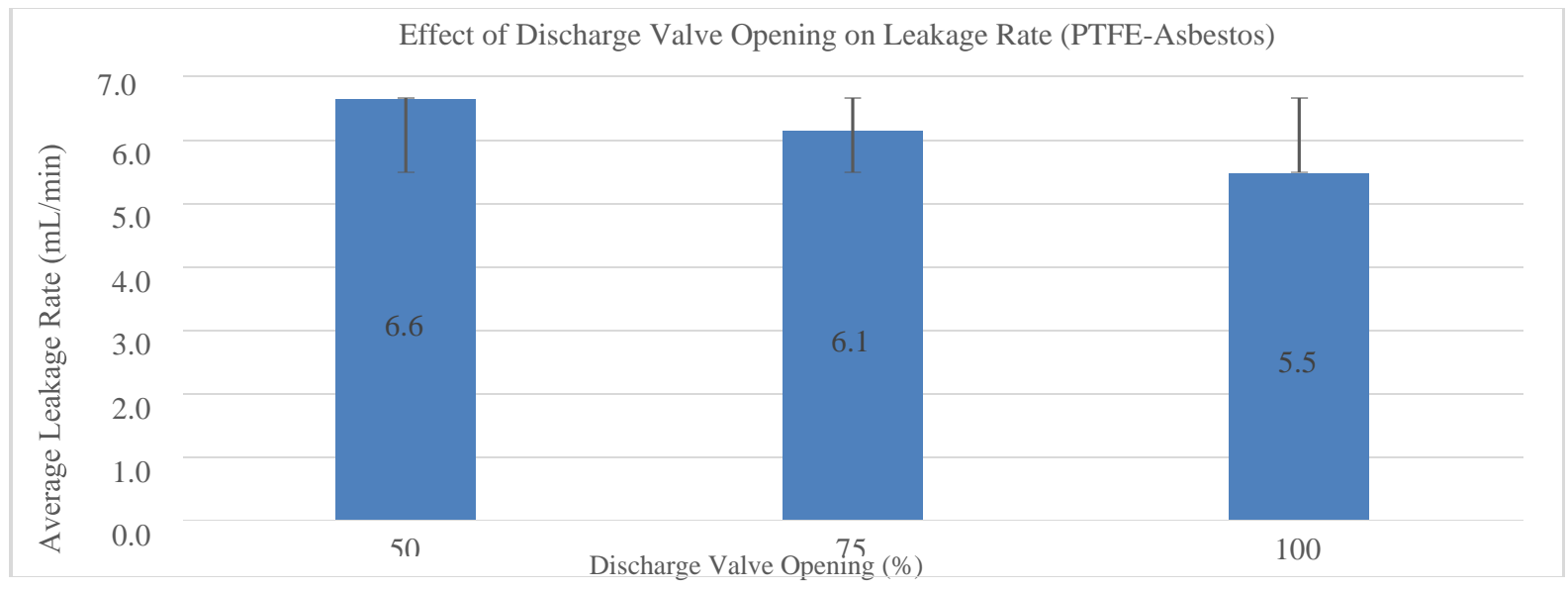

Figure 6: Effect of Pump Discharge Flow Rate on Leakage Rate (PTFE)

Based on this result, discharge valve opening does have a significant effect on the leakage rate because of the important differences recorded when throttled from $50 \%$ to $100 \%$. The highest leakage rate was recorded for PTFE-asbestos packing when the discharge valve was throttled at $50 \%$ with $6.6 \mathrm{~mL} / \mathrm{min}$, equivalent to approximately 132 drops per minute. Meanwhile, the lowest leakage rate for PTFE-asbestos packing was obtained when the discharge valve was throttled at $100 \%$ with $5.3 \mathrm{~mL} / \mathrm{min}$, equivalent to approximately 106 drops per minute. Therefore, a lower discharge valve opening would cause a higher leakage rate. This phenomenon happened because when the discharge valve was partially opened, it introduced higher resistance to the pumped liquid to move out of the pump due to obstruction at the discharge valve. This resulted in higher pressure created in the pump casing, and partial of the pumped liquid has no choice but to escape through its stuffing box, which has less pressure than the discharge line. 


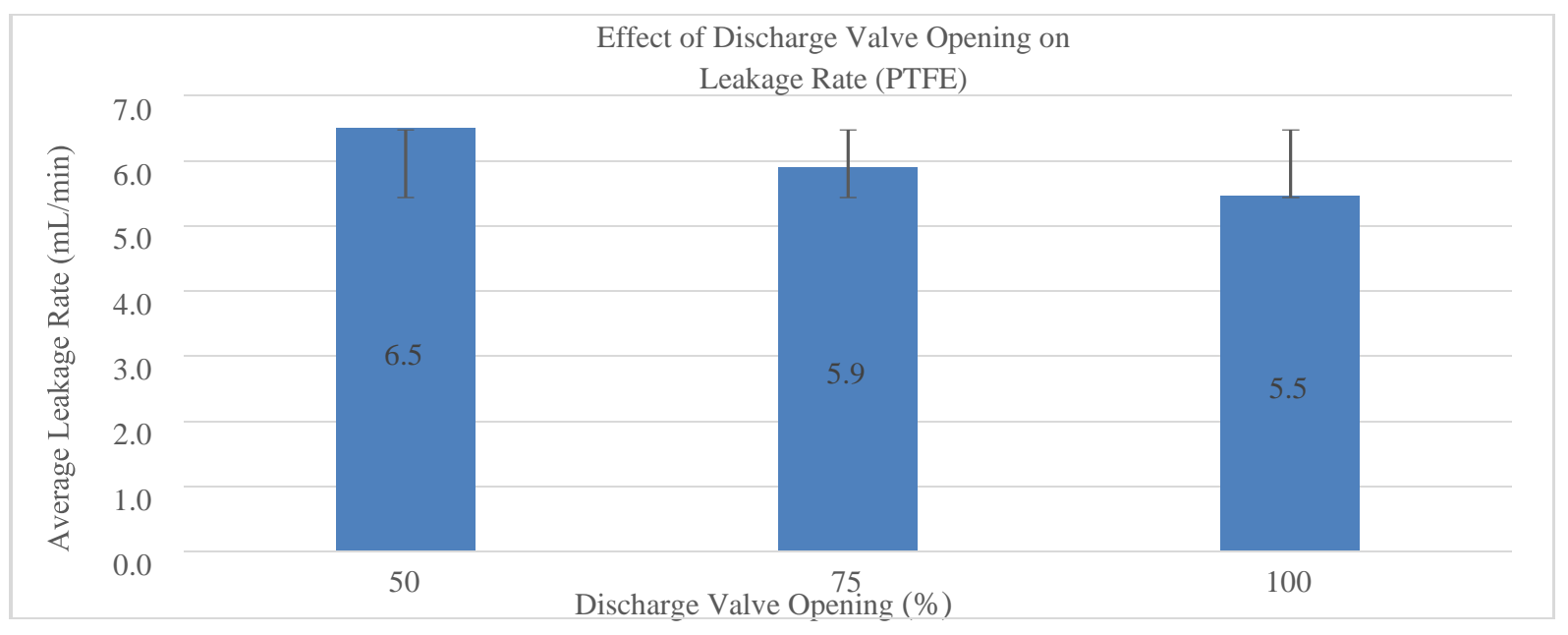

Figure 7: Effect of Pump Discharge Flow Rate on Leakage Rate (PTFE-Asbestos)

Samples of discharge pressure during flow rate at 50\% and 100\% were recorded and displayed slight differences. The discharge pressure had reduced by 0.3 barg after the discharge valve was throttled from $50 \%$ to $100 \%$ open. The leakage rate is reduced when the discharge valve opening is at $100 \%$. Nevertheless, during regular operation, the pump discharge will be throttled according to process requirements. Therefore, the pump operator could not operate the pump at a $100 \%$ flow rate to minimize the leakage rate. There is an operating guideline based on the pump performance curve. Operating a pump beyond its permissible limit could harm the pump due to cavitation and recirculation [16].

\subsubsection{Effect of Packing Material}

To simplify the study of packing material effect, data is compared for packing from graphite, PTFE, and PTFE-asbestos with a fixed size of $11 \mathrm{~mm}$ and discharge flow rate of $100 \%$. The effect of types of the packing material is shown in Figure 8. It is observed that graphite recorded the highest leakage rate with an average of $9.6 \mathrm{~mL} / \mathrm{min}$, while the lowest average leakage rate recorded was $9.2 \mathrm{~mL} / \mathrm{min}$, which was the average reading for PTFE-asbestos.

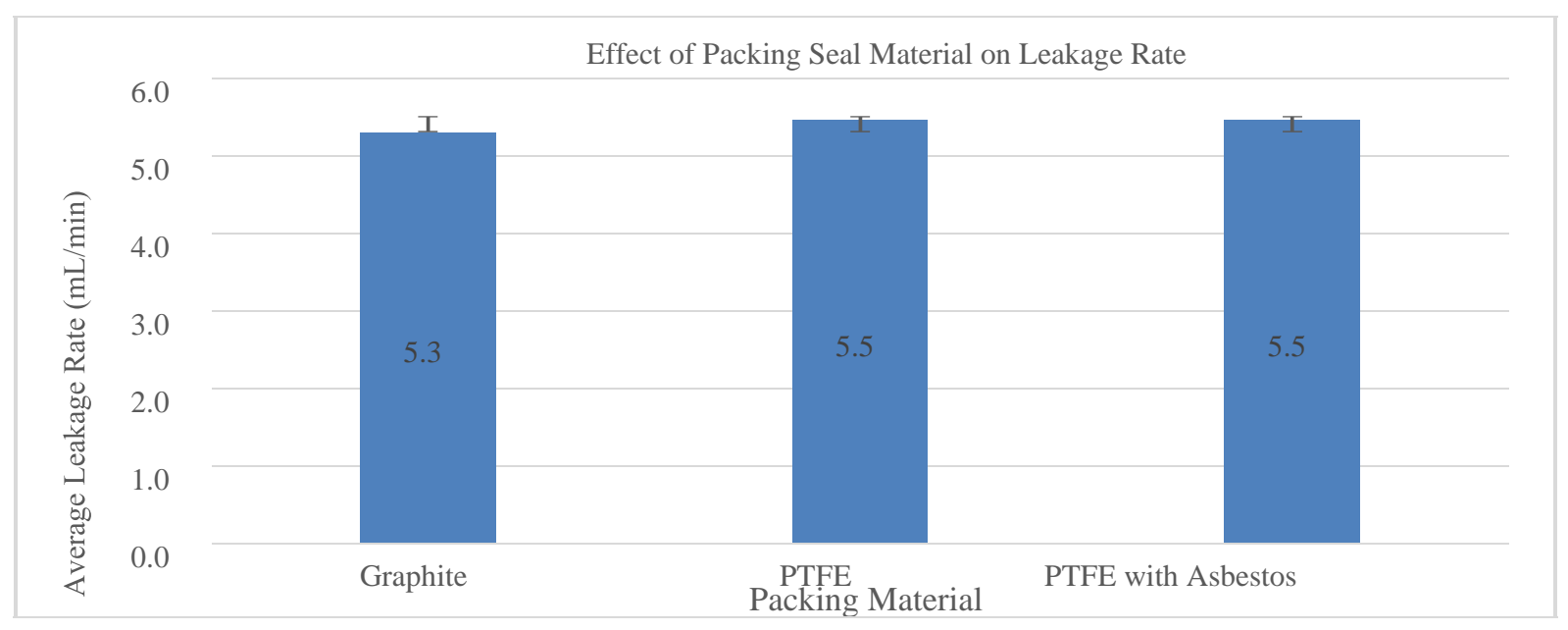

Figure 8: Effect of Packing Material on Leakage Rate

Based on this result, there is a slight difference between the highest leakage rate and lowest leakage rate at $0.2 \mathrm{~mL} / \mathrm{min}$, equivalent to $0.003 \mathrm{~mL} / \mathrm{sec}$. Although there are differences in the leakage rate 
recorded between the materials used for the packing, the amount is not significant. Therefore, packing material has an insignificant impact on the leakage rate. This is probably because the experiment's setup did not reflect the actual characteristics of the packing materials but was based on real operating conditions. Therefore, no significant differences could be observed, although graphite can withstand higher temperatures than PTFE and PTFE-asbestos. If the experiment was carried out at a higher temperature which is suitable for graphite and not for PTFE and PTFE-Asbestos, then probably a different set of results can be obtained. At $30^{\circ} \mathrm{C}$, the packing materials do not affect the pump leakage rate based on the result. Nevertheless, PTFE is the most suitable packing material due to its cleanliness and lower coefficient of friction that can minimize power consumption.

PTFE-Asbestos is not suitable due to its threat to people's health. Asbestos is a toxic chemical that can cause lung cancer, and its use was banned in 41 countries worldwide. In 2006, the International Labour Organization (ILO) had urged all countries to ban the use of asbestos. Control of asbestos usage in workplaces was carried out through legislation and enforcement of Factory and Machinery Act (Asbestos Regulation) 1986 and Occupational Safety and Health Act (Use and Standards of Exposure of Chemicals Hazardous to Health) 2000 on industries involved. This creates awareness and understanding among employers in addressing problems and controlling employees' exposure to asbestos material. Occupational Safety and Health Act (Prohibition of Use of Materials) 1999, including Crocidolite (Asbestos), also came into force on August 2, 1999, prohibiting Crocidolite chemicals in workplaces. In terms of cost, all materials are cost-effective, and there is not much difference. Therefore, the price of the packing material is not considered as a factor in packing selection.

\subsubsection{Feasibility Analysis on the Impact of Improvement Work}

Based on the experiment, the optimum setting for the packing is $11 \mathrm{~mm}$ size with a $100 \%$ discharge flow rate. Since packing material does not affect the leakage rate at this operating condition, the plant should use material that is safe to people and environment other than being economically viable, which is PTFE. With an average leakage rate at the optimum setting of $5.5 \mathrm{~mL} / \mathrm{min}$ compared to the present condition of $300 \mathrm{~mL} / \mathrm{min}$, the plant will save about $294.5 \mathrm{~mL} / \mathrm{min}$, equivalent to 141 liters for eight operating hours a day. That is almost equivalent to 94 bottles of 1.5-liter mineral water. This would increase the production yield and utility bill saving by optimizing treated water usage supplied by Syarikat Air Terengganu Sdn Bhd (SATU). The annual operating cost saving estimated from the improved leakage rate is MYR59.30, which could accumulate to MYR593.00 for ten years of operation for one pump. For ten similar pumps, cost-saving is estimated to be MYR5,930.00.

The calculation for the training plant is a bit different with operating hours for the pump is estimated at 8 hours per week. That makes 141 liters water saving for one week. Annual cost saving is estimated at MYR8.43, accumulating to MYR84.30 for ten years of operation for one pump. For ten similar pumps, cost-saving is estimated to be MYR843.00. Improved leakage rate could also contribute to fewer maintenance works over ten years of operation due to less corrosion and housekeeping. Corrosion could adversely affect the structural strength of the foundation, baseplate, and fittings for the pump. Therefore, it must be painted regularly according to plant standards to assure its integrity and reliability. Comparison between estimated existing and improved maintenance costs for one pump is tabulated in Table 3. A total of MYR221,200.00 maintenance cost savings can be achieved for ten pumps. The standard industry plant and training plant calculation is assumed to be almost the same due to an almost similar deterioration rate over the same period.

Apart from that, the improved leakage rate could also contribute to person-hours saving and preservation of treated water resources. Person-hours saving is important as it implies staffing costsaving and facilitates the manpower planning process that critical and urgent works to be attended to first and treated as a priority. Preservation of treated water resources means another step towards minimizing the effects of drought and water shortages, guarding against rising costs and political conflict, preserving our environment, making water available for recreational purposes, and building safe and beautiful communities. 
Table 3: Estimated Maintenance Cost Saving for A Pump

\begin{tabular}{lll}
\hline Item & Existing Maintenance & Improved Maintenance \\
\hline $\begin{array}{l}\text { Painting works } \\
\text { (Frequency/10 years) }\end{array}$ & 10 times/10 years & 3 times/10 years \\
\hline $\begin{array}{l}\text { Fitting replacement works } \\
\text { (Frequency/10 years) }\end{array}$ & 10 times/10 years & 3 times/10 years \\
\hline Est. Painting Works Cost & RM29,600.00 & RM8,880.00 \\
\hline $\begin{array}{l}\text { Est. Fitting Replacement } \\
\text { Works Cost }\end{array}$ & RM2,000.00 & RM600.00 \\
\hline Total Cost & RM31,600.00 & RM9,480.00 \\
\hline Cost Saving & RM22,120.00 & \\
\hline
\end{tabular}

\section{CONCLUSION}

The result showed clearly that at pump P-7301A operating condition, only packing size and discharge valve opening affect the pump leakage rate. Packing material did not affect the leakage rate at the pump operating condition. The optimum setting of packing for pump P-7301A is recommended as in Table 4.

With the new setting of packing being implemented, it is expected that the leakage rate can be reduced from $300 \mathrm{~mL} / \mathrm{min}$ to $5.5 \mathrm{~mL} / \mathrm{min}$. Less leak would contribute positively to production yield and operation cost optimization whereby MYR5,930.00 can be saved in 10 years of operation for ten pumps and further MYR221,200.00 for the maintenance cost. Apart from that, cleanliness at the pump foundation will be improved by reducing humidity levels because of delays in the algae growth rate. This can reduce the person-hours for cleaning and painting jobs. It can also preserve the environment through the optimization of treated water supply. Some limitations in conducting this experiment included high time consumption to set up the equipment for the experiment, such as packing replacement according to experiment configurations and manual discharge valve throttling according to experiment configurations. These involved pump downtimes, which could affect plant operation. Apart from that, access to specific plant operation details was also limited due to the company's confidentiality policy. Therefore, the impact on operation cost and maintenance cost could only be estimated based on previous experience. Future research and study recommend performing the same experiment for different pumps such as boiler feedwater pump that operates at higher temperature or plunger pump that uses reciprocating motion instead of rotary motion. This experiment will give better insights on the effect of material and size of packing seal and pump discharge flow rate on the leakage rate.

Table 4: Optimum Setting for Packing

\begin{tabular}{ll}
\hline Parameters/Properties & Description \\
\hline Size & $11 \mathrm{~mm}$ \\
Material & PTFE \\
Discharge Valve Opening & $100 \%$ \\
\hline
\end{tabular}




\section{REFERENCES}

[1] Liu, M., Tan, L., \& Cao, S. (2019). Theoretical model of energy performance prediction and BEP determination for centrifugal pump as turbine. Energy, 172, 712-732.

[2] Paresh Girdhar, O. M. and S. M. (2010). Practical Centrifugal Pumps: Design, Operation \& Maintenance. Newnes Publications

[3] American Petroleum Institute. (2012). Centrifugal Pumps for Petroleum, Petrochemical and Natural Gas Industries ANSI / API Standard 610, (October 2004)

[4] Turbomachinery International Staff. (2017). Interpreting seal leakage data. Magazine Turbomachinery International, (November 30), 1-3.

[5] Klinger's Stuffing Box Design and Installation of Compression Packings. (2010). KLINGER Ltd.

[6] Carroll Croarkin, P. T. (2001). One variable at a time. Journal of Research of the National Institute of Standards and Technology. Volume 106, Number 1.

[7] Vilarinho a, S., Lopes ${ }^{\mathrm{a}}$, I., \& Oliveira ${ }^{\mathrm{a}}$, J. A. (2017). Preventive maintenance decisions through maintenance optimization models : a case study, Procedia Manufacturing Volume 11, 2017, Pages 11701177.

[8] Nelson, W. Ed (1984). Maintenance And Troubleshooting Of Single-Stage Centrifugal Pumps. Turbomachinery and Pump Symposia Volume 1, Page 73.

[9] Josifovic, A., Roberts, J. J., Corney, J., Davies, B., \& Shipton, Z. K. (2016). Reducing the environmental impact of hydraulic fracturing through design optimisation of positive displacement pumps. Energy, 115, 1216-1233.

[10] Sorin, P., Aldea, A., \& Mădălin, M. (2017). ScienceDirect ScienceDirect Progresses in the operation and functioning of pumping stations for water and wastewater networks. Procedia Engineering, 209, 172179.

[11] Bianchi, G., Fatigati, F., Murgia, S., \& Cipollone, R. (2017). Design and analysis of a sliding vane pump for waste heat to power conversion systems using organic fluids. Applied Thermal Engineering, 124, 1038-1048.

[12] Mo, M., Husár, Š., Labaj, J., \& Žmindák, M. (2017). Non-stationary CFD simulation of a gear pump, Procedia Engineering Volume 177, Pages 532-539.

[13] Ferrante, M., Brunone, B., Meniconi, S., Capponi, C., \& Massari, C. (2014). The leak law : from local to global scale. Procedia Engineering, 70, 651-659.

[14] Salah, A., Aweimer, O., Bouzid, A., \& Kazeminia, M. (2017). Leak Rates of Gasses Through Packing Seals With Different Analytical. ASME 2017 Pressure Vessels and Piping Conference Volume 2: Computer Technology and Bolted Joints. https://doi.org/10.1115/PVP2017-65017

[15] International Organisation for Standardisation (2009) Mechanical vibration - Evaluation of machine vibration by measurements on non-rotating parts - Part 3: Industrial machines with nominal power above $15 \mathrm{~kW}$ and nominal speeds between $120 \mathrm{r} / \mathrm{min}$ and $15000 \mathrm{r} / \mathrm{min}$ when measured in situ (ISO 10816-3).

[16] Mackay, R. (2007). Pump installation \& piping. The Practical Pumping Handbook, 165-180. 